\title{
Culturas de intervenção pedagógica no reconhecimento do direito à educação
}

\author{
Nilda Stecanela \\ Universidade de Caxias do Sul - Brasil
}

Caroline Caldas Lemons

Universidade de Caxias do Sul - Brasil

\section{Resumo}

O texto objetiva refletir sobre como o direito à educação tem sido concebido, vivido e percebido pelos docentes da Educação Básica e de que modo as práticas de intervenção pedagógica favorecem seu reconhecimento. As reflexões, ancoradas na Teoria do Reconhecimento e no Direito à educação, consideram as narrativas de professores do Ensino Fundamental de uma rede pública municipal sul brasileira. A análise documental, instrumento semiestruturado, e o Grupo Focal foram utilizados na construção dos dados, resultando em cinco culturas de intervenção pedagógica.

Palavras-chave: Direito à educação. Intervenção pedagógica. Reconhecimento dos direitos.

\section{Resumen}

El texto objetiva reflexionar sobre cómo el derecho a la educación ha sido concebido, vivido y percibido por los profesores de Educación Básica y de qué modo las prácticas de intervención pedagógica favorecen su reconocimiento. Las reflexiones, ancladas en la Teoría del Reconocimi ento y en el Derecho a la educación, consideran las narrativas de profesores de la Enseñanza Fundamental de una red pública municipal del sur brasileña. El análisis documental, instrumento semiestructurado, y el grupo Focal fueron utilizados en la construcción de los datos, resultando en cinco culturas de intervención pedagógica.

Palabras-clave: Derecho a la educación. Intervención Pedagógica. Reconocimiento de los derechos.

\section{Abstract}

The text aims at reflecting on how the right to education has been conceived, lived and perceived by teachers of Basic Education and how practices of pedagogic intervention favor their recognition. The reflections, anchored in the Theory of Recognition and 
the Right to education, consider the narratives of elementary school teachers from a Brazilian municipal public network in southern Brazil. The documentary analysis, semistructured instrument, and focal Group were used in data construction, resulting in five cultures of pedagogical intervention.

Keywords: Right to education. Pedagogical Intervention. Recognition of Rights.

\section{Résumé}

Le texte vise à réfléchir sur la manière dont le droit à l'éducation a été conçu, vécu et perçu par les enseignants de l'éducation de base et sur la manière dont les pratiques d'intervention pédagogique favorisent leur reconnaissance. Les réflexions, ancrées dans la Théorie de la Reconnaissance et le Droit à l'éducation, portent sur les récits d'enseignants de l'école élémentaire d'un réseau public municipal au sud du Brésil. L'analyse documentaire, l'instrument semi-structuré et le groupe focal ont été utilisés dans la construction des données, donnant lieu à cinq cultures d'intervention pédagogique.

Mots-clefs: Droit à l'éducation. Intervention Pédagogique. Reconnaissance de droits.

\section{Contextualização inicial}

Em 5 de outubro de 2018, a Constituição Federal do Brasil completou 30 anos. E, no seu âmbito, está o direito à educação, especialmente expresso nos artigos 205 e 206. Durante esse período, houve crescente proliferação de políticas públicas educacionais voltadas à oferta da garantia jurídica ao direito universal à educação, acompanhadas de incipientes ou invisíveis considerações acerca do reconhecimento prático do direito à aprendizagem, nele subscrito, no âmbito escolar.

Decorridas três décadas desde sua promulgação, cabe indagar: como esse direito tem sido tratado na escola no sentido de garantir a aprendizagem e de que modo as práticas de intervenção pedagógica favorecem seu reconhecimento?

A busca por respostas ao expresso anteriormente impulsionou a definição da metodologia quali-quantitativa para o aprofundamento da análise dessas questões e requisitou a arquitetura de vários procedimentos para o rastreamento dos movimentos que o direito à educação assume no cotidiano da escola, considerando as dimensões do concebido nas políticas educacionais, do vivido nas práticas docentes e do percebido no pensar sobre a experiência pedagógica dos professores.

Uma vez que o recorte temporal da pesquisa compreendeu o período de trinta anos de vigência da atual Constituição Federal (1988-2018), o primeiro procedimento adotado foi a aplicação de um instrumento semiestruturado a doze docentes atuantes em uma 
das quatro escolas municipais que possuíam o Ensino Fundamental completo no ano de 1988, especificamente no Segundo Segmento do Ensino Fundamental (EF), $6^{\circ} \mathrm{s}$ aos $9^{\circ} \mathrm{s}$ anos. Os participantes (75\% mulheres com idades entre 21 e 51 anos) responderam a questões sobre sua trajetória profissional e educação.

O segundo procedimento, um grupo focal, teve como critério para a participação a formação (inicial) para a atuação nos anos finais do EF e o tempo de experiência no magistério público municipal. A amostra foi composta por seis professoras, com idades entre 28 e 63 anos, sendo duas ingressantes no magistério municipal em período anterior a 1988 e quatro com até dez anos de experiência caracterizando, respectivamente, um grupo que acompanhou a mudança legal que incluiu o direito à Educação Básica na jurisdição nacional e um grupo que já a encontrou estabelecida.

As conclusões do estudo apontam que ainda há muito para ser feito a fim de que haja reconhecimento do direito à educação, todavia indicam progressiva adoção de práticas de mediação pedagógica ${ }^{1}$ que convergem para uma maior horizontalidade e estima social. Além disso, os entrelaçamentos das políticas educacionais com as ideias pedagógicas e as narrativas docentes confirmam a existência de práticas pedagógicas com a intenção de intervir e favorecer os processos de aprendizagem que ocorrem nos espaços formais de educação e alongam-se temporalmente, as denominadas culturas de intervenção pedagógica.

Ante essas considerações, este texto inicia pela reflexão sobre os pressupostos jurídicos e filosóficos do direito à educação; em seguida, apresenta um breve retrospecto histórico-jurídico acerca do direito à educação no país, problematizando o hiato entre o instituído e o vivido nas políticas educacionais; e, por fim, expõe as narrativas docentes e as categorias de intervenção pedagógica emergentes do corpo empírico da pesquisa, de modo a fundamentar a discussão que relaciona o reconhecimento do direito à educação às culturas de intervenção pedagógica.

\section{Luta pelo reconhecimento}

Considerando: (a) que o direito à educação no Brasil, como bem público, subjetivo e gratuito a que todos os cidadãos têm o direito de possuir e requerer e que o Estado tem o dever de assegurar e prover, somente se deu a partir de 1988; (b) que a escola (regular) é ainda uma importante instituição de socialização, privilegiada quando se trata das condições concretas necessárias à efetivação do direito à educação; parece fundamental entender os pressupostos básicos das políticas educacionais em relação às práticas que se dão no cotidiano de quem as vive, se o desejo é ter o direito à educação reconhecido.

1 "Mediação, em termos genéricos, é o processo de intervenção de um elemento intermediário numa relação; a relação deixa, então, de ser direta e passa a ser mediada por esse elemento". (OLIVEIRA, 1997, p. 26, grifos da autora 
Ainda que reconhecê-lo envolva a dimensão jurídica, Honneth (2003) explica que o reconhecimento prático, tão importante quanto o jurídico para a autorrealização do sujeito, é mais complexo, pois implica que algo que está juridicamente assegurado seja legitimado coletivamente através de ações que reafirmem os princípios legais, sem que seja preciso recorrer a qualquer forma de persuasão ou penalidade.

Em se tratando de direito à educação, seria como se todos, especialmente os professores, uníssonos quanto à concepção de direito à educação - em que o direito à aprendizagem é subjacente -, adotassem práticas que o favorecessem cotidianamente, de forma horizontal e independente das condições concretas disponíveis nas escolas. Logicamente, as materialidades são fundamentais e podem contribuir para o desenvolvimento das práticas, mas a presença ou a ausência delas não pode servir para justificar omissões, visto que o direito a aprender não admite distinções. Nessa perspectiva, o que se insiste é que:

[...] o sistema jurídico precisa ser entendido de agora em diante como expressão dos interesses universalizáveis de todos os membros da sociedade, de sorte que ele não admita mais, segundo sua pretensão, exceções e privilégios. (HONNETH, 2003, p. 180-181).

Assim sendo, como explicar que, transcorridos trinta anos desde a introdução do direito à educação na Constituição e sua reafirmação em normativas complementares, muitas práticas pedagógicas permaneçam inalteradas nas escolas públicas de todo o país? O que fazer para que o instituído se aproxime do que é efetivado (ou não) pelos docentes no cotidiano escolar e vice-versa?

Inicialmente, pontua-se que o hiato entre o instituído pelas políticas educacionais e o vivido pelos professores nas escolas tem muitas razões. Mas, talvez a mais significativa esteja relacionada às diferentes concepções de educação e de direito à educação que permeiam os espaços escolares. Sem culpabilizar os docentes, pois isso em nada acrescentaria a esta discussão. A questão que merece ser problematizada diz respeito às práticas que têm sido desdobradas das apropriações que esses fazem das políticas educacionais, visto que isso representa a legitimação ou não das mesmas.

As práticas pedagógicas, enquanto condutas rotineiras processadas pelos professores quando na relação com os estudantes, com o currículo escolar e a gestão, para citar alguns, são aquelas do exercício profissional nas quais, dentre outras atribuições, os docentes desenvolvem os processos de ensino. Entendidas desse modo, ao adotar certas práticas de intervenção ${ }^{2}$, não apenas o professor deixa transparecer uma determinada concepção de educação, como também acaba colaborando (ou não) para que o direito à educação seja reconhecido para além da jurisprudência.

2 Etimologicamente, a palavra intervenção, do latim interventio - ônis, de interventum, supino de intervenir, pode significar: "ato de intervir, de interpor sua autoridade, de colocar-se entre". (CUNHA, 2012, p. 362) 
Sendo assim, interessa "desvendar", por intermédio das percepções de dezoito docentes, quais práticas de intervenção pedagógica têm sido adotadas no cotidiano da Educação Básica para inferir como o direito à educação tem sido vivido e se é possível falar em direito reconhecido.

Deste modo, se um demasiado número de práticas docentes pouco converge para impulsionar a aprendizagem, possivelmente, elas indiquem uma concepção de direito à educação ainda restrita à garantia do acesso, por exemplo. Contudo, se ocorre um esforço para identificar o nível de aprendizagem do estudante e são feitas tentativas diferenciadas para que esse avance em direção a níveis superiores, pode-se inferir que essa intervenção pedagógica sugere uma concepção de direito à educação mais alargada.

Mesmo a Base Nacional Comum Curricular (BNCC), aprovada no final de 2017, não traz uma definição específica ou explícita sobre direitos de aprendizagem e desenvolvimento. Sem aprofundar a questão, contudo, pode-se afirmar que tais direitos se desdobram da concepção de direito à educação aqui destacada, ou seja, que considera os aspectos que favorecem e/ou que subsidiam a aprendizagem e o desenvolvimento, sejam eles a intervenção pedagógica, a metodologia de ensino, o currículo, ou outros.

Apesar da perspectiva influente da jurisdição, esta não é (ainda) suficiente para assegurar ações docentes com vistas à efetivação do direito à educação. Acreditase, inclusive, que parte das diferenças entre o que se concebe e o que se opera a partir dessa concepção de direito tenha relação com a ausência de discussão sobre as próprias políticas educacionais, pois embora os textos estejam ao alcance da leitura de todos, talvez não estejam sendo revisitados em profundidade pelos professores.

A partir dos dados empíricos construídos na pesquisa (entre 2014 e 2015), foi possível, por exemplo, não somente identificar a permanência de algumas práticas pedagógicas, mas localizar a existência de algumas culturas de intervenção pedagógica $(\mathrm{CIP})^{3}$. As CIP emergem como desdobramentos das práticas (que podem ser todos os dias novas e originais) e aproximam-se das culturas escolares (que guardam em si um caráter permanente), uma vez que permanecem por um tempo razoavelmente longo, tornando-se reiteradas e consolidadas.

Assim, mesmo que haja muitos movimentos entre a tradição e a inovação das práticas docentes - motivadas ou não pelos contextos históricos ou legislativos -, algumas continuam sendo acessadas, em um determinado espaço, ainda que não tenham sido sistematizadas.

3 As culturas de intervenção pedagógica que emergiram na categorização dos dados empíricos serão detalhadas no próximo item. 
A categorização de culturas de intervenção pedagógica de reprodução, recomendação, disciplina, outorga/transferência e emancipação ${ }^{4}$ - a partir de narrativas de professores iniciantes e experientes que vivenciaram a transição entre a ausência e a presença de políticas educacionais que passaram a prever a educação como direito e dever públicos, não apenas demonstra que nem sempre a política é o motor para as mudanças que se almeja para a Educação Básica, como também permite que se questione até que ponto o direito à educação tem sido reconhecido na escola e o quanto as intervenções pedagógicas têm se desviado ou potencializado as políticas educacionais.

\section{Direito à educação}

Quando, em 1948, a Organização das Nações Unidas (ONU) tornou pública a Declaração Universal dos Direitos Humanos (DUDH), o mundo tentava reconstruir suas estruturas arrasadas pela Segunda Guerra Mundial. Mesmo sem ter força legal, a DUDH recomendava o direito à educação como um dos direitos sociais a ser efetivado por todas as nações que almejavam a manutenção da paz mundial. Decorrente dela, Convenções e Tratados foram escritos no intuito de reforçar e dar base legal a essa recomendação. Contudo, consoante as afirmativas de McCowan:

Ainda assim, o direito legal à educação revela-se uma estranha miscelânea: é específico e prescritivo em relação a alguns aspectos e omisso em relação a outros. Surpreendentemente, é específico no tocante às formas institucionais que devem garantir a educação e à duração desta, mas, a despeito de algumas recomendações gerais sobre objetivos, não é específico quanto aos tipos de processos realizados nessas instituições. (McCOWAN, 2011, p. 11).

Esse paradoxo apontado por McCowan, situado entre a prescrição e a omissão, fez com que o direito à educação no Brasil fosse explicitado, pela primeira vez na Constituição Federal de 1988, como um direito de todos os brasileiros e um dever do Estado, sem que houvesse naquele momento uma discussão sobre a concepção de direito à educação que se tinha.

A atenção estatal então se voltou para o que era mais urgente: abrir escolas e assegurar o ingresso e a permanência do maior número de estudantes possível. Conforme tal movimento foi acontecendo, outras políticas educacionais complementares foram sendo desdobradas, pormenorizando os aspectos práticos relativos à educação básica e aos sujeitos de direito, como: o Estatuto da Criança e do Adolescente (Lei 8.069/90), a Lei de Diretrizes e Bases da Educação Nacional (Lei 9.496/96), as Diretrizes Curriculares Nacionais que, em 2013, substituíram os Parâmetros Curriculares Nacionais, o Plano Nacional de Educação (2014-2024) e, mais recentemente, a BNCC.

$4 \quad$ As categorias emergentes do corpo empírico da pesquisa, mobilizadas pelas orientações da análise textual discursiva (adiante explicitada), foram construídas em razão das recorrências em que apareceram nas narrativas escritas e orais dos docentes participantes da pesquisa. 
Com elas, aos poucos, tem sido possível perceber um movimento de deslocamento da concepção inicial de direito à educação, trazida superficialmente na Constituição e aquela que veio sendo desenhada nos documentos posteriores. No início, em razão do contexto e dos altos índices de analfabetismo que assolavam o país, a urgência estava em garantir vagas em escolas. Superada (ainda que não na totalidade) essa demanda, o Estado brasileiro passou a demonstrar preocupação com os aspectos subjetivos do direito à educação. Conforme esclarece Andrade:

Quando se fala em direito à educação, o mais recorrente é associá-lo ao acesso à escola. Assim, num primeiro momento, parece que este direito se restringe à obrigatoriedade de cumprir certa quantidade de anos numa instituição de educação formal. É bastante comum reduzi-lo às referências jurídicas. (ANDRADE, 2013, p. 21).

O Estado, ao ultrapassar a incipiente ideia de direito à educação, embora não tenha deixado de entendê-lo como o direito de frequentar uma escola pública e gratuita, falando-se objetivamente, tem passado a concebê-lo em perspectivas mais ampliadas, considerando os processos subjetivos que se dão no interior da escola. McCowan afirma que o direito à educação passou a envolver o direito à aprendizagem enquanto um processo contínuo e que se dá ao longo da vida, portanto, algo para além de "[...] um conjunto de resultados fixos de conhecimentos, habilidades e valores; na verdade, trata-se de uma experiência fluída, de desenvolvimento constante". (McCOWAN, 2011, p. 15).

O problema é que sendo a educação um direito social subjetivo, que implica em direito à aprendizagem para sua efetivação, é importante que haja o reconhecimento prático por toda a coletividade a quem o direito se destina e com quem ela se faz. Isto porque, embora a legislação seja importante, sozinha não é (ainda) capaz de assegurar mudanças proporcionais nos mecanismos de funcionamento escolar estruturados há décadas, como é o caso brasileiro.

Reconhecer o direito à educação em sua essência, que é a aprendizagem, implica no entendimento da minúcia dos textos jurídicos e também que se adentre a escola, movimente o olhar da dimensão do concebido (legislado) para o vivido (praticado) e vice-versa, de modo a tentar compreender como se dão as intervenções pedagógicas que buscam favorecer a aprendizagem.

A aprendizagem faz parte daquilo que é experienciado, construído entre os sujeitos por intermédio da relação pedagógica; está na esfera do dinâmico e do sensível e, por tantos fatores invisiveis, quase nunca pode ser atestada. Então, como fazer a aprendizagem acontecer na escola? Para Reale (2002, p. 42), "[...] como nem todos podem ou querem realizar de maneira espontânea as obrigações morais, é indispensável armar de força certos preceitos éticos, para que a sociedade não soçobre".

Sabe-se da dificuldade que é efetivar a aprendizagem para todos visto que a questão demanda, em alguns casos, condições concretas de realizabilidade, em geral econômicas - que nem sempre o Estado tem meios para arcar - e, em outros casos, a assunção do 
dever pelos docentes. De todo modo, ambas requerem investimentos que, para Bobbio, tornam os direitos subjetivos muitas vezes irrealizáveis:

O campo dos direitos do homem - ou, mais precisamente, das normas que declaram, reconhecem, definem, atribuem direitos ao homem - aparece, certamente, como aquele onde é maior a defasagem entre a posição da norma e sua efetiva aplicação. E essa defasagem é ainda mais intensa precisamente no campo dos direitos sociais. (BOBBIO, 1992, p. 77).

Bem, reconhecer o direito à educação significa concebê-lo em toda a complexidade e amplitude que um processo permanente de aprendizado, como é o processo de educação, exige. Ter direito à educação é ter direito a aprender, de forma flexível, diversa e compatível com seu nível de desenvolvimento, por intermédio de intervenções adequadas, dialógicas e amorosas. Para Freire (2013), uma intervenção pedagógica que deve acontecer mediada pelo respeito aos saberes dos educandos, pela reflexão crítica sobre a prática e pelo reconhecimento da identidade cultural de modo que o desenvolvimento das habilidades e competências pelo educando the permitam formar conceitos, construir conhecimentos e constituir saberes que the acompanharão e serão fundamentais para a vida toda.

Honneth (2003), na Teoria do reconhecimento, explica que são três as formas de reconhecimento a que uma pessoa pode pretender e alcançar: a primeira está no amor; a segunda, na jurisprudência; a terceira, na estima social. Candau e Sacavino (2013), autores que corroboram a perspectiva honnethiana referente à terceira forma de reconhecimento, dispõem que é pela correspondência entre a teoria e a prática, feita no cotidiano, que um direito pode ser assegurado e que, portanto, não há como pensar o direito à educação sem pensar a intervenção pedagógica, pois é por intermédio dela, dos estímulos que o professor faz, dos comportamentos que legitima pela horizontalidade do agir, pela relação equânime e pelo diálogo aberto, que a política encontra correspondência e legitimidade. Em suas palavras:

Ser sujeito de direitos implica reforçar no cotidiano, através de práticas concretas, a lógica expansiva da democracia, afirmar o princípio e o direito da igualdade estabelecidos na esfera jurídica e política e transportar essa dinâmica igualitária para as diversas esferas da sociedade. (CANDAU; SACAVINO, 2013, p.62).

As políticas não possuem, sozinhas, meios para mobilizar os professores para que concebam o direito à educação pela via do direito a aprender que cada sujeito tem, respeitadas suas singularidades, potencialidades e seus saberes de experiência. As políticas adentraram a escola, mas não sensibilizaram a todos. Não foram e possivelmente nunca serão capazes de alterar todos os processos de socialização que se dão no cotidiano escolar e nas práticas de intervenção pedagógica para que a aprendizagem seja amplamente alcançada por todos.

Não há dúvidas de que o direito à educação trouxe movimentos. A intervenção pedagógica tem sido cada vez mais requisitada, seja pelo Estado, seja pelos estudantes. Aliás, com estudantes dotados de tantos saberes de experiências feitos, como denominou Freire (2013), como não ser o professor mais exigido? 
Ao tomar aspectos da teoria de Vigotskii para pensar a aprendizagem, tem-se como princípio que a criança, ao iniciar sua trajetória na educação escolar, já possua alguns saberes de acordo com a etapa de desenvolvimento em que se encontra. Esses saberes "espontâneos", relacionados à maturação do próprio organismo, corresponderiam ao seu nível de desenvolvimento real. Oliveira (1997, p. 56), ancorada nessa teoria, explica que esse percurso de desenvolvimento, que vai daquilo que a criança já sabe para o que ela já tem capacidade de aprender, portanto que lhe é potencial e "[...] em parte definido pelo processo de maturação do organismo individual [...]", somente é despertado pela via da aprendizagem quando há interação entre indivíduos em certo ambiente cultural uma vez que, para desenvolver todas as suas potencialidades, a criança necessita do auxílio deliberado de um adulto.

Esse processo não está restrito à infância, pelo contrário, com os adolescentes que frequentam o Segundo Segmento do EF, ifnterações e intervenções adequadas também são condições essenciais para que haja aprendizagem. E é por isso que na escola, é função docente atuar no interstício entre o real e o potencial; entre o que o estudante já sabe e o que ele poderá vir a saber. Atuando na chamada zona de desenvolvimento proximal, o professor favorece tanto a aprendizagem quanto o desenvolvimento, visto que ambos são processos interligados. Para os autores:

[...] a característica essencial da aprendizagem é que engendra a área de desenvolvimento potencial, ou seja, que faz nascer, estimula e ativa na criança um grupo de processos internos de desenvolvimento no âmbito das inter-relações com outros, que, na continuação, são absorvidos pelo curso interior de desenvolvimento e se convertem em aquisições internas da criança. Considerada deste ponto de vista, a aprendizagem não é, em si mesma, desenvolvimento, mas uma correta organização da aprendizagem da criança conduz ao desenvolvimento mental, ativa todo um grupo de processos de desenvolvimento, e esta ativação não poderia produzir-se sem a aprendizagem. Por isso, a aprendizagem é um movimento intrinsecamente necessário e universal para que se desenvolvam na criança essas características humanas não naturais, mas formadas historicamente. (VIGOTSKII; LURIA; LEONTIEV, 2001, p. 115).

A intervenção pedagógica adquire relevância ainda maior diante dos deslocamentos de sentido - do direito à educação para o direito à aprendizagem - e da abrangência que tem acompanhado as políticas educacionais, seja por intermédio de mecanismos para sua reafirmação ou sua reinvenção no âmbito escolar. Os modos de fazer docentes não são apenas importantes para o conhecimento sobre o cotidiano da Educação Básica Nacional, mas para o reconhecimento do direito à educação.

Nessa perspectiva, interlocutores empíricos foram convidados para dialogar com os interlocutores teóricos da pesquisa. Saberes formais e informais, percursos sociais e profissionais, individuais e coletivos, se entrecruzaram e compuseram um conjunto de narrativas, escritas e orais, de professores iniciantes e experientes, atuantes nos últimos anos do EF da Rede de Ensino observada.

Tratadas pela perspectiva da análise textual discursiva proposta por Moraes e Galiazzi (2007), essas narrativas passaram por um conjunto de etapas (impregnação, imersão, unitarização, descrição e categorização) e compuseram uma escrita reconstrutiva 
que, como explicam os autores, "[...] implica em superar a mera aderência as ideias de outros, para assumir nos textos escritos argumentos próprios, expondo as próprias ideias". (MORAES; GALIAZZI, 2007, p. 14-15).

Com a possibilidade de aprofundar as questões inicialmente formuladas, de dar visibilidade aos achados do percurso e de dialogar com os interlocutores teóricos e empíricos da pesquisa, foi possível aprofundar a compreensão inicial que se tinha sobre o direito à educação.

Pelos motivos explicitados, o estudo sobre o direito à educação, que considerou as narrativas docentes sobre as práticas pedagógicas a partir das orientações legais subsequentes a Constituição Federal de 1988, permitiu que fossem identificadas cinco culturas de intervenção pedagógica.

\section{Culturas de intervenção pedagógica}

Na dinâmica escolar, a mescla de sujeitos, contextos e condições físicas, dentre tantos outros fatores, contribui para que as práticas de ensino sejam constantemente alteradas. Contudo, isso nem sempre acontece. Alguns elementos das práticas de intervenção pedagógica não foram substancialmente alterados ou substituídos no decorrer dos últimos trinta anos, evidenciando que as mudanças nas políticas educacionais não estiveram acompanhadas por mudanças práticas.

Foram identificadas práticas pedagógicas resistentes ao tempo e aos textos jurídicos, talvez alheias, subversivas ou desdobradas deles. Embora não possam ser acessadas por intermédio das narrativas reflexivas dos sujeitos da pesquisa, tais práticas, denominadas como sendo culturas de intervenção pedagógica, puderam ser representadas.

Assim, as culturas de intervenção pedagógica foram definidas como sendo as práticas de intervenção docentes, ancoradas ou não em referenciais teóricos ou normativas políticas, ativadas/vividas pelo professor com a intenção de favorecer a aprendizagem e que perduram por um tempo razoavelmente estendido. Expressam-se por meio das mediações verbais e não verbais dos professores aos estudantes, dentro ou fora da sala de aula, mas frequentemente experienciadas em espaço formal de educação no qual se interpõe o ensino planejado e o currículo previamente organizado, com definição de tempos e espaços para a construção dos conhecimentos, constituição de saberes e para as experiências de socialização.

Esses modos de intervir, em que alguns elementos se cristalizam cotidianamente nos espaços formais de educação, ocorrem a partir do instituído, mas sem necessariamente o reafirmarem. Assim, apesar da distinção conferida às CIP, não se desconsidera que já estivessem presentes no cotidiano da escola, em meio a outras culturas já percebidas e discutidas, mas talvez não tivessem sido ainda definidas ou as tivessem sido distintamente nomeadas. 
Categorizá-las, aliás, apresentou-se como um grade desafio, pois como salienta Botía (2002, p. 16), trabalhar com narrativas implica em "lograr un equilibrio entre una interpretación que no se limite, desde dentro, a los discursos de los entrevistados, ni tampoco una interpretación, desde fuera, que prescinda de los matices y modulaciones del discurso narrado". Assim sendo, a análise e a interpretação levaram em conta as trajetórias e experiências profissionais vividas por cada um dos sujeitos professores a fim de não incorrer no erro de generalizá-las ou menosprezá-las.

Tomando esses cuidados foi possível, a partir das três questões mobilizadoras propostas no instrumento semiestruturado: (1) "Como é ser professor hoje?", (2) "Quais são as maiores dificuldades?" e (3) "Quais as alegrias?" e, dos três temas discutidos no Grupo Focal: (1) "Mais de vinte e cinco anos de direito à educação: significados, desafios, alegrias e dificuldades?", (2) "A educação é um direito e uma obrigação. Há implicâncias no processo de ensino e de aprendizagem?" e (3) "Sobre a aprendizagem, o que você faz para que ela aconteça?", dar relevância às narrativas ${ }^{5}$ em si, trazendo para a discussão as muitas vozes dos protagonistas escolares privilegiados na pesquisa - os professores.

Como resultado, cinco culturas de intervenção pedagógica foram categorizadas:

\section{Culturas de reprodução}

Considerando que quase a totalidade dos professores que respondeu ao instrumento semiestruturado afirmou que a aprendizagem é manifestada no desempenho teórico, entendido como sendo aquele expressado em provas, trabalhos ou outros instrumentos, deduz-se que, por meio deles, seja possivel ao professor verificar a aprendizagem e atestar a não aprendizagem.

De fato, existe essa possibilidade. Contudo, se a aprendizagem formal não é a única aprendizagem que se efetiva na escola e que o estudante não internaliza o que recebe culturalmente, de forma passiva; ao contrário, ele a transforma, ativa, efetua sínteses, a impregna de sentidos, seria apropriado considerar avaliar também processos como: o ganho de autonomia, a qualidade em se expressar, a iniciativa, o posicionamento frente às questões cotidianas, a aplicação dos conhecimentos na solução dos problemas sociais, políticos ou mesmo familiares.

Quando narrativas como "porque não adianta, se o aluno apresentou uma dificuldade, eu retomar da mesma forma" ou "o sistema tem que se reinventar" emergem, com recorrência, há evidências de que a educação continua a ser pensada a partir de conteúdos e como movimento que independe dos sujeitos. A exigência de reinvenção é por si mesma indicadora de que o fazer docente não ultrapassa, muitas vezes, a mesmice e a reprodução de práticas confortáveis e seguras. 
Foram algumas dessas iniciativas e proposições docentes que não ultrapassam a dimensão da reprodução de conteúdos, das experiências e dos modos de ensinar e avaliar, explorados maciçamente nas últimas décadas - e que, ainda que ocorram adequações, são raras ou pouco significativas as reinvenções -, que originaram as culturas de reprodução.

As práticas pautadas pelo retorno das informações, pela revisão dos conteúdos e pela repetição de explicações se destacaram. Iniciativas de flexibilização dos instrumentos avaliativos, a observância do desempenho da turma como um todo, indicando que condições mais individualizadas possam estar sendo desprezadas, suscitam o entendimento de que as tentativas de diálogo professor-estudante-família, as atividades e os trabalhos extras, por vezes, têm tido pouca importância.

\section{Culturas de recomendação}

Especialmente nos debates do Grupo Focal, o paradoxo que trata a educação como um direito e também como uma obrigação esteve presente e indicou que nem sempre os professores têm clareza de suas responsabilidades profissionais, polarizando o papel da família e da escola.

Reflexões destacando como "trabalhar como pagar uma conta, arrumar uma cama, lavar uma louça", "fazer com que eles vejam significado nisso [conteúdo]', "para que ele [estudante] leve para vida dele e aplique de alguma forma" e "ver os alunos na faculdade e/ou em um bom emprego" dão indícios de algumas questões invisíveis presentes no cotidiano docente.

Narrativas acompanhadas de forte crítica à família, como a de que "todos têm direito à educação, porém atualmente apenas os professores têm a obrigação de desenvolver a educação" e "o direito é da criança e a obrigação de garantir esse direito é da família através do acompanhamento da vida escolar de seu filho" ou "ter que estar ligando para casa, ter que estar ameaçando a família, com $\mathrm{FICAl}^{6}, \mathrm{com}$ ' $n$ ' formas porque não são capazes de mandar [...] o filho ir para a escola", também alertam para o problema acerca das responsabilidades.

Frequentemente, a participação dos pais no processo educativo foi reclamada, especialmente nas questões que envolvem o cuidar. Para algumas professoras, ao mesmo tempo em que a democratização levou todos para a escola, ela também trouxe uma série de problemas, pois a obrigatoriedade de estar na escola conclamou todas as diferentes famílias para dividir os mesmos espaços, alterando as identidades que acessam as instituições de ensino.

Nesse sentido, o encontro de diferentes culturas culminou na assunção de novas responsabilidades por parte dos docentes a fim de que a escola básica se adequasse ao 
novo público. Resistentes, alguns não admitem (ou não sabem) que a si cabe educar, tanto quanto cuidar as crianças e adolescentes que lá estão.

De alguns anos para cá, com o aprofundamento do modelo capitalista pelo mundo e a inserção da mulher no mundo do trabalho, o cuidado com as crianças e os adolescentes precisou ser partilhado, e em consequência, a escola tem sido cada vez mais exigida. A impotência, retratada por alguns, ficou evidenciada com a narrativa de que "estamos em uma época em que as famílias estão em crise e a escola está assumindo esse papel, mesmo sem preparação adequada para isso".

Apesar disso, ainda que tenha sido a minoria, há docentes com o entendimento de que também são suas as responsabilidades de cuidar e ensinar. Têm consciência de que "às vezes, a escola subestima um pouco a participação dos pais e o entendimento que os pais têm da importância da escola". Sabem que "os pais querem que os filhos estudem, mas houve uma distância muito grande daquela geração autoritária que a gente veio para essa geração permissiva" e, por conta disso, a tarefa de educar os jovens se tornou mais complexa e abrangente.

Diante dos arranjos e características que envolvem as novas organizações familiares, relacionadas às exigentes estruturas econômicas atuais, outros modos de intervir têm sido requisitados. Às culturas de recomendação, tipificadas do corpo empírico da investigação, correspondem as variadas indicações, conselhos e recomendações que os professores fazem aos estudantes em relação aos modos de aprender, cuidar de si, acessar informações, construir relações entre seus conhecimentos e a realidade social ou ainda cuidar dos outros, dentro ou fora da escola.

\section{Culturas de disciplina}

As diferentes culturas que têm dividido os espaços escolares, sobretudo públicos, provocam certa nostalgia nos docentes mais experientes. A falta sentida em relação às antigas formas de frequentar a escola reverberaram em narrativas de denúncia, tais como "os alunos que não querem estudar atrapalham os colegas", "a falta de interesse dos alunos em aprender a matéria", o "desrespeito de alunos, pais e comunidade em geral", o "tempo gasto chamando atenção", "o mau comportamento dos alunos", e deixaram implícito a existência do desejo de "que alguns alunos não estivessem na escola".

Por vezes, parece que os professores querem o silenciamento dos estudantes, dessa geração que exige mudanças nos processos educativos, seja demonstrando desinteresse ou fazendo excessivo barulho, pois assim não seria preciso mudar a escola, não seria preciso qualificar-se ou, quem sabe, continuar aprendendo.

Não há dúvidas de que, em outros períodos históricos, ser professor não exigia tanto. Não há como pensar que sejam os mesmos sentidos atribuídos à escola décadas atrás. 
Entender que "não se aprende só na sala de aula, só sentado" e que "não é que essa geração não tenha foco, não consiga se concentrar; ela não consegue se concentrar para aquilo que ela não quer" ainda desafia muitos docentes. Presos às experiências de outrora, em que "era mais tranquilo; tinha a questão da autoridade da família", não percebem que "o grande desafio da escola é justamente dar conta dessa diversidade".

A seu modo, essas narrativas exemplificam as culturas de disciplina, voltadas tanto para a sujeição do estudante quanto para o exercício de sua cidadania frente aos regramentos sociais em geral, ou seja, tanto no sentido de dificultar ou impedir sua expressão quanto no sentido de mostrar maneiras responsáveis, organizadas e respeitosas de estar no mundo e com os outros.

\section{Culturas de outorga/transferência}

A falta de uma rede de atendimento psicopedagógico em conjunto com a escola também emergiu com força. Narrativas como "[seriam necessários] profissionais da saúde - psiquiatra, psicóloga, fonoaudióloga, pediatra, neurologista - à disposição da educação/escola", "se nas escolas tivessem pessoas para o cargo do SOE , psicólogas, assistentes sociais, elas nos ajudariam e também a família participaria mais", "não ter formação nem auxílio de especialistas para identificar ou diagnosticar alunos que apresentam limitações de aprendizagem" expuseram a importância dessa rede de atendimento.

Contudo, há um contraponto importante: a terceirização da intervenção pedagógica. Diz-se isso pois há uma linha muito tênue entre a busca por mais subsídios teóricos e aparatos profissionais e a atribuição da "culpa" do insucesso escolar e da não aprendizagem para outros profissionais. Essa outorga, não raras vezes, ronda o espaço escolar e orienta as ações ou a inatividade de alguns professores. Além disso, expõe a tendência de medicalização/patologização de estudantes que vem sendo bastante popularizada no Brasil.

As culturas de outorga/transferência apontam, portanto, em duas direções: o encaminhamento dos estudantes "indisciplinados" para outros profissionais e instituições a fim de que sejam acompanhados - ou punidos - e também, a busca por apoio multiprofissional no intuito de que os estudantes possam receber atendimento complementar necessário para a superação das dificuldades de aprendizagem.

De modo mais específico, nesse tipo cultural de intervenção pedagógica é comum ocorrer tanto a transferência total da responsabilidade docente, com vistas a não assumi-la (quando delega a outro - membro da escola, da família ou profissional - a responsabilidade profissional que the cabe), quanto à transferência parcial (atuação conjunta). Nesse segundo caso, o objetivo é salvaguardar o estudante e congregar

Serviço de Orientação ao Estudante. 
esforços para que suas potencialidades possam ser plenamente desenvolvidas.

\section{Culturas de emancipação}

Parte significativa das dificuldades apontadas pelos docentes diz respeito ao perfil dos estudantes e de suas famílias, para o modo como essas se importam (ou não) com a educação de seus filhos ou como ambos se relacionam com a escola, indicando que há sim uma preocupação com os que estão adentrando as escolas.

Mesmo tímidas, as narrativas de vivências que priorizam o trabalho coletivo para o sucesso das experiências escolares e que buscam o encontro das diferentes culturas e visões de mundo e o respeito à trajetória pessoal, familiar e escolar dos estudantes também estiveram representadas. Na síntese reflexiva de uma das professoras participantes do Grupo Focal, "quando se pensa a questão de garantir o acesso, tem também que se pensar se aquilo que está sendo trabalhado, a forma como está sendo avaliado, a forma como a escola está sendo organizada; se ela chama a atenção. Ela dá essa possibilidade para que os alunos se sintam pertencentes daquela escola?", a necessidade de subverter o modelo que persiste é imprescindível.

Para as professoras experientes, se a escola não buscar alternativas para as práticas, não irá educar e cuidar do estudante e tampouco dará conta de sua principal atribuição que é ensinar. Entendem que a escola não é o único local de aprendizagem e estão dispostas a se desafiarem propondo situações novas e adotando diferentes recursos metodológicos.

Partilhando experiências musicais e manuais, como a "Orquestra, Coro e Flautas e [o] Papel Reciclado" e "situações de alunos sendo oficineiros", vão ao encontro do entendimento reiterado por elas de que "a prova e o final, não existem", que "um período [não] é suficiente para efetivar a aprendizagem" e de que são necessários "mais momentos de aprendizagem". Indicam, ainda, atenção para as aprendizagens que fogem ao conhecimento formal ou conceitual.

Com o olhar e a escuta sensíveis, percebem que no momento do ensino os sentidos estão sendo construídos e que nem todos os estudantes farão a mesma aplicação das experiências propiciadas pela educação escolar. "Esse respeito à individualidade, ao ritmo de cada um para aprender é uma coisa que é muito forte na escola", conforme expõe uma das colaboradoras da pesquisa. Apesar de não haver receitas prontas, várias experiências apresentam resultados positivos, tais como "os reagrupamentos" e a "oficina de aprendizagem".

A adoção de estratégias como planejamentos diferenciados em uma mesma turma ou a partir de "temas que os alunos gostam, como: tecnologia, notícias, esportes e guerras" são, nas palavras dos docentes, "fantásticas para que o aluno também perceba que a escola tem a ver com algumas coisas que ele gosta". 
Por sua especificidade, as culturas de emancipação compreendem as reinvenções docentes, a ampliação dos modos de socialização e dos estímulos às descobertas que, em geral, fogem das condutas mais tradicionais exemplificadas, pois carregam o inusitado, conduzem a novos arranjos pedagógicos, apostam em projetos voltados para o desenvolvimento da criatividade, buscando tornar concreta a ideia de autoformação integral dos sujeitos em processo de escolarização.

As aproximações dos sentidos que os professores atribuem às suas próprias narrativas não somente refletem significâncias que atingem tanto professores iniciantes quanto professores experientes no magistério municipal, mas também são reprodutoras de concepções que fazem parte das culturas escolares de um determinado período em virtude de um processo de formação inicial e continuada, de políticas nacionais e locais etc.

Apesar das diferenças entre si, essas CIP não podem ser hierarquizadas, apenas interconectadas, visto que não raramente ocorrem simultaneamente, mobilizadas por um mesmo professor. Ainda que não seja possível afirmar de que maneira cada qual potencializa a aprendizagem, se pode afirmar que, a seu modo, cada uma cumpre uma função importante nos processos escolares.

Além de que, estudá-las permite compreender parte do que é potencialmente vivido nas escolas e quais tipos de intervenções pedagógicas têm sido privilegiadas pelos professores. Amplamente, no âmbito do estudo sobre o direito à educação, essas categorias mostram que os sujeitos que adentraram a escola ainda não possuem a visibilidade que os textos jurídicos os relegam, visto que os arranjos pedagógicos pouco se alteraram com suas presenças.

Também não houve alterações significativas na reflexão que os professores iniciantes e experientes fazem sobre o direito à educação, razão pela qual eles não foram diferenciados no texto. Em geral, suas narrativas se limitam à obrigatoriedade do ensino para todos, pois entendem que essa é a prerrogativa legal. Aliás, sobre esse aspecto, embora todos sejam unânimes quanto ao conhecimento das políticas educacionais em vigor, poucos já se dedicaram à leitura dos textos e a maioria não se acha responsável por sua efetivação e, embora os colaboradores concordem que a garantia desse direito passa por torná-lo obrigatório, questionam as garantias que estão sendo oferecidas.

Por tudo que foi dito, as narrativas sinalizam que há ainda uma distância significativa entre a intenção, a regulação e a prática, talvez fruto de entendimentos rasos e superficiais do real significado do direito à educação. Contudo, enquanto isso não for superado, não será possível falar em reconhecimento do direito à educação. 


\section{Considerações finais}

O direito à educação vai além dos muros da escola, contudo, nela há a possibilidade real e potencial para que seja reconhecido por uma coletividade social expressiva. É no cotidiano escolar que a maioria dos sujeitos passa parte importante de seu tempo de vida, tem oportunidades de ser, aprender, fazer e socializar com pessoas de outras culturas, valores e crenças.

Pela riqueza que compõe o cotidiano escolar, os processos educacionais não podem se restringir ao repetitivo, sem a consideração dos sujeitos para quem a educação se destina e com quem deve ser construída. Um dos caminhos para que o direito à educação possa ser reconhecido pela coletividade é justamente este: extrapolar o entendimento objetivo da lei por meio da consideração das subjetividades envolvidas, seus anseios e necessidades, assegurando aos estudantes descobertas, experiências e relações.

Sem menosprezar os demais aspectos relacionados ao reconhecimento do direito à educação, por intermédio das narrativas docentes sobre suas experiências na Educação Básica, parece razoável afirmar que a efetivação do direito à educação ainda depende de rupturas ao que se opera na escola. Embora não seja possível indicar como fazê-las, o que se pode dizer a respeito é que vai demandar muito trabalho reflexivo, coletivo e contextualizado para quem e com quem a educação escolar se destina, pois não parece mais ser possivel pensar a intervenção pedagógica sem os estudantes.

Reconhecer o direito à educação é uma questão de superar a falta de simetria, as discriminações e as distinções entre quem se escolhe estimar e quem se escolhe invisibilizar e nisso o professor tem um papel muito importante, mas para fazê-lo precisa se propor a conceber a educação de outro modo. Enquanto se olha para as responsabilidades públicas - que são muitas e devidas - esquece-se que a intervenção pedagógica responde por parte significativa do reconhecimento do direito, pois dentro da escola a lei se faz por intermédio da relação pedagógica.

Talvez se aproximando das realidades, dos saberes e das necessidades dos sujeitos escolares e refletindo sobre os aspectos que precisam ser revistos, os professores possam potencializar o desenvolvimento dos processos psíquicos que somente se desenvolvem mediante intervenções que, em se tratando de educação (escolar), são deflagradas por eles.

Há avanços, não se pode negar. Ao menos foi possível perceber nas narrativas docentes certa abertura e sensibilidade nessa direção, mas isso ainda está longe de representar as ações coletivas. A potencialização de práticas convergentes é responsabilidade e dever docente e aplicar a lei é obrigação de quem está dela investido.

Por fim, entende-se que enquanto houver compreensão díspar de direito à educação, não haverá direito reconhecido. E, sendo assim, é parte do caminho a insistência de que discutir as políticas educacionais continua sendo condição para superar os desafios que 
se relacionam à aprendizagem.

\section{Referências}

Andrade, M. (2013). É a educação um direito humano? Em busca de razões suficientes para se justificar o direito de formar-se como humano. Educação, 36(1), 21-27. Retrieved from http://revistaseletronicas.pucrs.br/ojs/index.php/faced/article/view/12294

Bobbio, N. (1992). A era dos direitos. (C. N. Coutinho, Trans.) (11th ed.). Rio de Janeiro: Elsevier.

Botía, A. B. (2002). “¿De nobis ipsis silemus?": Epistemología de la investigación biográfico-narrativa en educación. Revista Electrónica de Investigación Educativa, 3(1), 1-26. Retrieved from https://redie.uabc.mx/redie/article/viewFile/49/91

Brasil. (1990). Lei no 8069, de 13 de julho de 1990. Dispõe sobre o Estatuto da Criança e do Adolescente. Retrieved from www.planalto.gov.br/ccivil_03/LEIS/L8069.htm

Brasil. (1996). Lei no 9394, de 20 de dezembro de 1996. Estabelece as diretrizes e bases da educação nacional. Retrieved from http://www.planalto.gov.br/ccivil_03/Leis/ L9394.htm

Candau, V. M. F., \& Sacavino, S. B. (2013). Educação em direitos humanos e formação de educadores. Educação, 36(1), 59-66. Retrieved from http://revistaseletronicas.pucrs. br/ojs/index.php/faced/article/view/12319

Cunha, A. G. (2012). Dicionário etimológico da língua portuguesa. Rio de Janeiro: Lexikon. Retrieved from http://ucs.bv3.digitalpages.com.br/users/publications/9788586368899/pages/363

Freire, P. (2013). Pedagogia da autonomia: Saberes necessários à prática educativa (45th ed.). Rio de Janeiro: Paz e Terra.

Honneth, A. (2003). Luta por reconhecimento: A gramática moral dos conflitos sociais. (L. Repa, Trans.). São Paulo: Editora 34.

McCowan, T. (2011). O direito universal à educação: Silêncios, riscos e possibilidades. Praxis Educativa, 6(1), 9-20. https://doi.org/10.5212/PraxEduc.v.6i1.0001

Moraes, R., \& Galiazzi, M. do C. (2007). Análise textual discursiva. ljuí: Editora Unijuí.

Oliveira, M. K. de. (1997). Vygotsky: Aprendizado e desenvolvimento um processo sócio-histórico. São Paulo: Scipione.

Reale, M. (2002). Lições preliminares de direito (27th ed.). São Paulo: Saraiva. 
Vigotskii, L. S., Luria, A. R., \& Leontiev, A. N. (2001). Linguagem, desenvolvimento e aprendizagem. (M. P. Villalobos, Trans.) (7th ed.). São Paulo: İcone.

\section{Biografia}

\section{Nilda Stecanela}

Doutora em Educação pela Universidade Federal do Rio Grande do Sul. Pró-Reitora Acadêmica, docente do corpo permanente do Programa de Pós-Graduação em Educação da Universidade de Caxias do Sul e Co-editora da Revista Conjectura: Filosofia e Educação. Coordena o Observatório de Educação da mesma instituição. É bolsista CNPq de Produtividade em Pesquisa.

E-mail: nildastecanela@gmail.com / ORCID: https://orcid.org/0000-0001-99460848

\section{Caroline Caldas Lemons}

Professora de História formada pela Fundação Universidade Federal do Rio Grande e especialista em Rio Grande do Sul: Sociedade, Política \& Cultura pela mesma instituição. É mestre em Educação pelo PPGEd da Universidade de Caxias do Sul na linha de pesquisa História e Filosofia da Educação e cursa o Doutorado em Educação no mesmo Programa. Atua como professora da Rede Municipal de Ensino de Caxias do Sul. Bolsista Prosuc/ Capes. Professora na Rede Municipal de Ensino de Caxias do Sul.

E-mail: carolemons@ibest.com.br / ORCID: https://orcid.org/0000-0003-41788036 